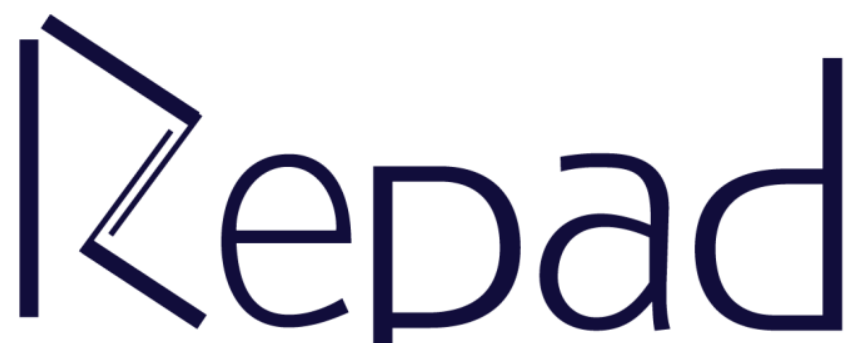

Revista Estudos e

Pesquisas em Administração 


\title{
GESTÃO DE PESSOAS NA EDUCAÇÃO: A importância do trabalho coletivo na consecução de resultados educacionais
}

\author{
Nilson Robson Guedes Silva \\ Faculdade de Conchas, Conchas, São Paulo, Brasil \\ nguedes29@gmail.com \\ https://orcid.org/0000-0003-0321-8112
}

\begin{abstract}
Resumo
O trabalho apresentado é resultado de uma pesquisa baseada em estudos exploratórios, de natureza bibliográfica e abordagem qualitativa, que teve como objetivo geral analisar a importância do trabalho coletivo nas instituições de ensino, para atingir seus objetivos. Após discutir as questões que envolvem Gestão Educacional, Gestão Empresarial, Gestão de Pessoas, a dimensão humana em Gestão de Pessoas e Qualidade de Vida no Trabalho, foi demonstrado que a administração escolar poderá ter um desempenho melhor se houver uma participação da comunidade escolar por meio de trabalho coletivo. A gestão democrática, incluindo uma maior participação da comunidade nas decisões de interesse coletivo, deve ser permanentemente perseguida e planejada por todos, considerando sua importância na consecução dos objetivos estabelecidos pelas instituições de ensino.
\end{abstract}

Palavras-chave: Gestão de Pessoas; Administração Educacional; Trabalho Coletivo.

\section{GESTIÓN DE PERSONAS EN LA EDUCACIÓN: La importancia del trabajo colectivo para alcanzar los resultados educativos}

\section{Resumen}

El trabajo presentado es el resultado de una investigación basada en estudios exploratorios, naturaleza bibliográfica y enfoque cualitativo, que tuvo como objetivo general analizar la importancia del trabajo colectivo en las instituciones educativas, para lograr sus objetivos. Después de discutir los temas relacionados con la gestión educativa, la gestión empresarial, la gestión de personas, la dimensión humana en la gestión de personas y la calidad de vida en el trabajo, se demostró que la administración de la escuela podrá desempeñarse mejor, actuando en un Los resultados educativos se logran si la comunidad escolar participa a través del trabajo colectivo. La gestión democrática, en la que se incluye una mayor participación de la comunidad en las decisiones de interés colectivo, debe ser perseguida y planificada permanentemente por todos, considerando su importancia para lograr los objetivos establecidos por las instituciones educativas.

Palabras clave: Gestión de personas; Administración educativa; Trabajo colectivo.

\section{PEOPLE MANAGEMENT IN EDUCATION: The importance of collective work in achieving educational outcomes}

\begin{abstract}
The work presented is the result of a research based on exploratory studies, with bibliographical nature and qualitative approach, which had as its general objective to analyze the importance of collective work in educational institutions, to achieve their goals. After discussing the issues involving Educational Management, Business
\end{abstract}


Management, People Management, the human dimension in People Management and Quality of Life at Work, it has been shown that school administration will be able to perform better if there is a participation of the school community through collective work. Democratic management, including greater community participation in decisions of collective interest, must be permanently pursued and planned by all, considering its importance in achieving the goals set by educational institutions.

keywords: People management; Educational administration; Collective work.

Submetido: 30/10/2019

Aceito: 16/12/2019

Publicado: 31/12/2019

\section{INTRODUÇÃO}

A presente pesquisa, situada no campo da 'Gestão de Pessoas', pretendeu analisar a importância do trabalho coletivo em instituições educacionais, para que os objetivos previstos sejam alcançados. Muitas instituições podem não alcançar as suas metas pela existência de uma gestão que não aproveita todas as potencialidades de seus funcionários, e não organiza as suas atividades para que os seus colaboradores atuem coletivamente. No caso de escolas, os seus diretores, ao não valorizarem esse aspecto da gestão (gestão de pessoas), contribuem para que muitas instituições educacionais apresentem resultados insatisfatórios.

Para identificação da importância de um trabalho coletivo em escolas, e sua relação com os resultados alcançados, foram definidas as seguintes questões norteadoras: Qual a relação entre gestão empresarial e gestão educacional? Qual a especificidade da gestão educacional? Em que se constitui e qual a abrangência de uma gestão de pessoas, em uma organização? Qual a importância da dimensão humana na gestão? Qual a especificidade da gestão de pessoas em escolas? De que forma o gestor pode atuar para a construção de um trabalho coletivo? Qual a importância do coletivo para que os resultados sejam alcançados?

Os resultados da pesquisa podem contribuir com o trabalho dos gestores escolares, ao se considerar que a literatura existente aborda, com maior abrangência, a gestão de pessoas em empresas, que estão organizadas de forma diferente. Ao abordar a organização do trabalho coletivo em escolas, com o enriquecimento da literatura que discute o mesmo tema em empresas, denota-se a importância da pesquisa para os diretores de escola, que poderão refletir sobre o trabalho que desenvolvem e sobre a importância da gestão de pessoas em uma atividade que busca o alcance de objetivos essencialmente pedagógicos.

O objetivo geral foi analisar a importância do coletivo para o alcance dos resultados educacionais. Quanto aos objetivos específicos, foram os seguintes: apontar a relação existente entre gestão empresarial e educacional; identificar a especificidade da gestão escolar e da gestão de pessoas na escola; conhecer a abrangência da gestão de pessoas na organização, e a importância da dimensão humana nas relações entre os colaboradores; descrever a forma pela qual o gestor pode atuar para a construção de um trabalho coletivo; e relatar a importância do trabalho coletivo para que os resultados educacionais sejam alcançados.

O trabalho, resultado de uma pesquisa bibliográfica, desenvolvido a partir da análise de obras de autores que discutem a temática, tem o seu início marcado pela 
apresentação de um breve histórico sobre a administração educacional no Brasil, sendo apontada a relação entre a gestão educacional e a empresarial, e a influência desta última na área da educação. Na sequência, é apresentada uma conceituação sobre gestão de pessoas e, posteriormente, é discutida a dimensão humana na gestão de pessoas e a qualidade de vida no trabalho. A gestão de pessoas em instituições educacionais, e as especificidades encontradas na área da educação, são objetos de análise na sequência, introduzindo a discussão que envolve o trabalho coletivo em instituições educacionais, e a sua importância para o alcance dos resultados educacionais.

\section{ENSAIO TEÓRICO}

O presente trabalho, baseado em estudos exploratórios, foi desenvolvido através de uma pesquisa bibliográfica, de abordagem qualitativa, sendo adotadas as fases descritas por Marconi e Lakatos (2017, p. 44): “a) escolha do tema; b) elaboração do plano de trabalho; c) identificação; d) localização; e) compilação; f) fichamento; g) análise e interpretação; e h) redação". Essa modalidade de pesquisa é valorizada enquanto um procedimento metodológico de importância para a produção do conhecimento científico "[...] capaz de gerar, especialmente em temas pouco explorados, a postulação de hipóteses ou interpretações que servirão de ponto de partida para outras pesquisas" (LIMA; MIOTO, 2007, p. 40).

Gil (2017) aponta como objetivo do estudo exploratório possibilitar uma maior proximidade com o problema da pesquisa, de forma que ele se torne mais explícito, possibilitando que ideias sejam aprimoradas e intuições descobertas.

A pesquisa bibliográfica, que tem como base para o seu desenvolvimento materiais já elaborados, possui um grande número de fontes a serem consultadas. Gil (2017, p. 64), reconhecendo a existência de "[...] pesquisas em que os dados obtidos a partir de fontes bibliográficas são utilizados de maneira exclusiva", indica como fontes os livros, publicações periódicas e impressos diversos. O desenvolvimento de uma pesquisa bibliográfica exige, do pesquisador, após a apreensão dos objetivos que se pretende alcançar, leitura de uma ampla bibliografia, questionamentos e “[...] interlocução crítica com o material bibliográfico que permite, por sua vez, um leque de possibilidades na apreensão das múltiplas questões que envolvem o objeto de estudo" (LIMA; MIOTO, 2007, p. 40). Foram buscadas referências para cada um dos temas discutidos no trabalho, sendo, posteriormente, estabelecidas relações entre eles, de forma que houvesse uma coerência entre as diferentes partes da pesquisa, e possibilitasse o alcance dos objetivos pretendidos.

\section{GESTÃO EDUCACIONAL E GESTÃO EMPRESARIAL: CAMPO DE TENSÕES}

Nem sempre o tema 'administração educacional' recebeu atenção na produção bibliográfica brasileira, sendo devidamente estruturada na academia há menos de 100 anos. Drabach e Mousquer (2009) relatam que, no Brasil, os primeiros escritos teóricos sobre administração educacional são de 1930, o que, para os autores, não significa afirmar que inexistia prática de administração escolar no Brasil até esta data. Para os autores, a ausência de produção de um corpo teórico sobre administração educacional decorre do descaso dos governantes, que não construíram para a população um sistema de ensino. 
Na década de 1930, tinha-se um contexto educacional acadêmico inserido nos ideais de uma educação progressista, com a influência do movimento Escola Nova, que se voltava contra a educação tradicional, considerada desfavorável aos ideais do desenvolvimento do país, e, assim, contrária ao avanço da industrialização. Os educadores brasileiros que integravam o movimento da Escola Nova defendiam que o campo educacional deveria se pautar por uma maior cientificidade, e que teriam que ser oferecidas mais vagas para a população. Esses educadores afirmavam que os problemas da administração educacional deveriam ser resolvidos com a utilização de um maior espírito filosófico e científico, e que essa carência era a responsável principal pela desorganização escolar. (DRABACH; MOUSQUER, 2009). A partir desse movimento, foi iniciada a produção teórica no campo da administração educacional, tendo como alguns de seus representantes os seguintes autores: Leão (1945); Teixeira (1961; 1964; 1997); Lourenço Filho (1970) e Ribeiro (1986). Nas décadas iniciais do século XX, momento em que o espírito de cientificização estava latente, a administração esteve fortemente influenciada pela administração geral, fruto das elaborações científicas, que era considerada a alternativa mais adequada, uma vez que obtinha sucesso no âmbito empresarial. Na década de 1980, momento em que houve um forte questionamento da racionalidade do capitalismo no campo da educação, o modelo da administração científica empresarial foi fortemente questionado, caminhando para que a centralidade técnicaadministrativa fosse retirada do campo da educação (DRABACH; MOUSQUER, 2009).

Com a Constituição de 1988, que estabeleceu o princípio da gestão democrática na educação pública, houve novos debates e olhares sobre a gestão educacional, surgindo um intenso debate sobre a influência da administração empresarial na educação, o que era criticado por muitos educadores. Para Russo (2013), uma administração escolar comprometida com a transformação social torna-se totalmente diferente da administração empresarial (capitalista), considerando que a escola deverá atuar para que os trabalhadores dominem o saber ${ }^{1}$, de forma que desenvolvam uma consciência crítica da realidade (educação libertadora) e se libertem da dominação a que estão sujeitos e das desigualdades sociais.

Abordando, também, sobre a necessária especificidade da Administração Educacional, Paro (2018) inicia as suas considerações sobre o tema afirmando que, de forma geral, a administração pode ser entendida como a administração de recursos de forma racional, para que se realizem determinados fins, através do esforço humano de uma determinada coletividade. $\mathrm{O}$ autor considera que, em uma administração capitalista, a relação ocorrida entre as pessoas é pautada pela dominação, e as relações que ocorrem entre trabalho e capital é de exploração. Paro propõe que se pense a racionalidade das ações da humanidade, avaliando ser necessária a busca de objetivos que atendam aos interesses de todos os integrantes da sociedade, e não apenas de determinados grupos sociais. Para essa mudança de paradigma, o autor considera ser necessário que ocorra uma verdadeira transformação na forma de organização social. E para essa transformação, torna-se necessário uma escola transformadora, que necessita de uma administração comprometida com esse mesmo objetivo. Portanto, não há como transferir

1 A instituição escolar tem como função social transmitir aos alunos (transmissão ativa) a herança cultural da humanidade, ou seja, a escola deve sintetizar milhares de anos da história da humanidade para atualização cultural do público que atende, de forma que o ser humano não precise " viver todos os estágios por que passaram as gerações que nos antecederam para repetir as experiências que produziram a humanidade do homem. Em outras palavras, ele não precisa 'redescobrir a roda'”. (RUSSO, 2013, p. 2). 
automaticamente para a escola o princípio da administração empresarial, uma vez que seus objetivos não são os mesmos.

Russo (2013), ao analisar o processo de produção que ocorre na escola (processo de produção pedagógico) e o processo produtivo de uma empresa (produção de bens materiais), vê diferenças significativas entre as duas instituições. Para o autor, as diferenças se situam tanto nas peculiaridades do processo em si, quanto, também, nos objetivos que as instituições buscam alcançar. Se na sociedade capitalista a produção tem como objetivo exclusivo a produção de mercadorias, a instituição educacional deve buscar a formação e a emancipação do homem, para que ele goze de autonomia e de igualdade. Outra diferença apontada pelo autor é que, diferentemente de uma empresa, o processo pedagógico desenvolvido na escola não é material, e o produto da escola não se separa na produção. Explica o autor que, na escola, a presença do aluno no processo produtivo é de fundamental importância.

\section{GESTÃO DE PESSOAS - BREVE CONCEITUAÇÃO CONTEMPORÂNEA}

Um princípio básico para quem quer trabalhar com o ser humano, é gostar de pessoas, é se sentir bem no meio de pessoas. Essa exigência é maior ainda para quem atua na coordenação de uma equipe. Para Boog (2010, p. 104), quem quer ser líder tem que se sentir bem com as pessoas, tem que "[...] gostar de gente, de lidar com a intrincada alma das pessoas. Existem pessoas que adoram a parte técnica, mas se sentem incompetentes para lidar com pessoas, com a diversidade e a imprevisibilidade de comportamentos que os humanos apresentam" (BOOG, p. 104). Ressaltando de forma enfática essa qualidade, diz ainda que pessoas sempre devem ser tratadas como pessoas, e nunca como 'recursos humanos'.

Dutra (2016) procura classificar as etapas do processo evolutivo da gestão de pessoas, tendo como parâmetro as funções desempenhadas pelos indivíduos nas instituições. Ao se verificar a abordagem funcionalista, por exemplo, podem ser identificadas 03 fases no processo histórico. A primeira fase, identificada de fase operacional, ocorreu até a década de 1960, e se caracterizava pela preocupação da gestão de pessoas em colocar em prática a captação, o treinamento, a remuneração e as informações. Já na segunda fase, denominada de fase gerencial, ocorrida no período de 1960 ao início de 1980, a gestão de pessoas começa a promover uma interferência nos processos da organização, e passa a ser solicitada a participar dos processos de desenvolvimento da organização. A partir dos anos 80 é iniciada a terceira fase, nomeada como fase estratégica, onde a gestão de pessoas passa a assumir um papel estratégico para que as pessoas internalizem novos conceitos, novas formas de pensamento, gerando valores para a organização (DUTRA, 2016). Dutra (2016) considera que os conceitos modernos de gestão, bem como as suas práticas, são mais eficientes para a obtenção de um maior comprometimento do colaborador com a organização. Havendo maior comprometimento, é possível que a empresa obtenha mais dedicação e maior produtividade e empenho do profissional, sem a necessidade de lhe oferecer uma vantajosa contrapartida. $\mathrm{O}$ autor afirma ainda que o desenvolvimento de pessoas se constitui na "habilidade do líder em estruturar, motivar e preparar sua equipe para as demandas de médio e longo prazo do negócio. Envolve a capacidade de promover um clima interno favorável à participação e oferecer oportunidades concretas de desenvolvimento" (DUTRA 2016, p. 30). 
Uma organização que procura se preparar para o futuro terá que investir em dois aspectos: um investimento em seu sistema de gestão de pessoas, visando a sua modernização, e o outro no estímulo e no suporte para que as pessoas busquem, de forma autônoma, o seu próprio desenvolvimento. Modernizar a gestão de pessoas significa dar condições para que a organização e os colaboradores possam vislumbrar o seu desenvolvimento, e, também, para que a instituição possa verificar de que forma todos os seus colaboradores poderão contribuir com o negócio, de maneira que empresa e colaborador conciliem, dinamicamente, as suas expectativas. Sem estímulo e apoio, as pessoas não refletem sobre o seu desenvolvimento, que é o detalhe para que o profissional tenha competitividade. Dutra considera que "[...] a questão do desenvolvimento é a pedra de toque para a competitividade profissional da pessoa e organizacional da empresa, a estimulação mútua nesse sentido será o alicerce para uma relação que pode suportar as adversidades do futuro". (DUTRA, 2016, p. 209).

\section{A DIMENSÃO HUMANA NA GESTÃo DE PESSOAS E A QUALIDADE DE VIDA NO TRABALHO}

Uma relação de conflito entre a organização e os seus colaboradores pode prejudicar a todos. Ozaki considera que relações de conflito entre a organização "[...] e todas as pessoas envolvidas precisam ser resolvidas para se criar condições melhores de trabalho e de relacionamento social, melhorando os aspectos psicossociais do trabalho, pois contribuirão para os resultados e o sucesso da organização" (OZAKI, 2009, p. 29). Alguns autores defendem a necessidade de uma Qualidade de Vida no Trabalho - QVT, o que poderá influenciar os resultados que se pretende alcançar. Davis define QVT como uma "[...] preocupação com o bem-estar geral e a saúde dos trabalhadores no desempenho de suas tarefas" (DAVIS apud CHIAVENATO, 2009, p. 448). Limongi-França considera QVT como "o conjunto das escolhas de bem-estar único e individualizado que proporciona autoestima positiva, percepção de equilíbrio, hábitos saudáveis e prontidão para o desempenho no trabalho saudável" (LIMONGI-FRANÇA, 2009, p. 275 apud OZAKI, 2009, pp. 32-33).

Davis e Newstrom (1996), também referidos por Ozaki (2009), compreendem que a proposta principal da Qualidade de Vida no Trabalho é a de desenvolver ambientes de trabalho que sejam bons, tanto para as pessoas como para a condição econômica da organização. Nesse entendimento, a proposta da Qualidade de Vida no Trabalho seria a de conhecer todos os pontos que podem ser favoráveis e desfavoráveis a um ambiente de trabalho mais humanizado, sendo buscado um equilíbrio entre as necessidades da organização e as dos colaboradores. "Nesse sentido, a tentativa da QVT é conhecer os pontos favoráveis e desfavoráveis do ambiente de trabalho, para torná-lo mais humanizado, equilibrando as necessidades tanto da organização como dos trabalhadores" (OZAKI, 2009, p. 32).

Chiavenato (2009) ressalta os seguintes aspectos da Qualidade de Vida no Trabalho: a incorporação de dois interesses antagônicos, onde se tem, de um lado, os interesses dos trabalhadores pela satisfação no trabalho e o bem-estar e o interesse das instituições sobre os impactos positivos que influenciam na produtividade e na qualidade; o respeito da organização pelos seus colaboradores; a motivação e a satisfação dos trabalhadores; e investimento no cliente interno, sendo considerado de igual valor ao 
investimento no cliente externo - assim, a satisfação do colaborador influencia na satisfação do cliente externo.

Para Limongi-França, citados por Ozaki (2009), é de fundamental importância que as organizações estimulem os trabalhadores, de forma que eles tenham o trabalho como fonte de prazer, o que os levará ao bem-estar e satisfação. Para o autor, toda pessoa possui potencialidades biológicas, sociais e psicológicas, tornando-a um complexo biopsicossocial. Assim, as organizações devem organizar as suas ações de forma que as pessoas se mantenham saudáveis. As organizações também devem proporcionar aos seus colaboradores o bem-estar, no sentido biopsicossocial, nos aspectos de proteção, de recuperação e de promoção da saúde. Quando se fala em práticas de proteção da saúde, significa a adoção de procedimentos que tenham como objetivo a prevenção das pessoas aos agentes nocivos (uso de equipamentos de proteção) e a prevenção de doenças. As práticas de recuperação e de promoção à saúde se referem ao desenvolvimento de práticas para recuperar as pessoas que já estão doentes.

Para o autor, o bem-estar deve estar relacionado à manutenção, de forma íntegra, do indivíduo como pessoa, profissional e cidadão. "O desafio para as organizações é 'reconstruir, com bem-estar, o ambiente competitivo, altamente tecnológico, de alta produtividade do trabalho, e garantir ritmos e situações ecologicamente corretas" (LIMONGI-FRANÇA, 2008, p. 45). Assim, preocupar-se com a Qualidade de Vida no Trabalho, controlando-a, "[...] é gerir riscos, mantendo a salubridade, isto é, um ambiente que propicie e privilegie a saúde no sentido biopsicossocial" (OZAKI, 2009, p. 38). Segundo a autora,

\begin{abstract}
Vale ressaltar a conceituação abrangente de saúde, que inclui componentes físicos, mentais, sociais e psicológicos do bem-estar, que foi proposta por Ryff e Singer e é composta por quatro elementos centrais: "1) viver uma vida com propósito; 2) ligações de qualidade com outras pessoas; 3 ) autoestima positiva e autodomínio; 4) percepção de acontecimentos negativos como caminhos para o sentido e o propósito" (RYFF; SINGER, 1998 apud MACIK-FREY, 2009, p. 97). Esses elementos são comuns entre as diversas culturas. Além dos riscos a que estão sujeitas as pessoas, há outros riscos aos quais estão sujeitas as organizações: 1) contaminação de produto; 2) danos a terceiros; 3) morte de colaboradores; 4) danos ao meio ambiente; 5) explosões; 6) incêndios; e 7) roubos e fraudes. As principais consequências podem envolver: 1) riscos à vida; 2) perda de clientes; 3) perda da credibilidade; 4) queda nas vendas; 5) prejuízos à imagem organizacional; 6) paralisação das atividades; 7) prejuízos financeiros e 8) demissões (RIBEIRO, 2005 apud OZAKI, 2009, pp. 37-38)
\end{abstract}

Dessa forma, fica nítido que uma relação saudável entre os colaboradores e a organização traz benefícios tanto para as pessoas quanto para a instituição, o que justificativa o empenho de todos na busca desse objetivo.

\title{
4. A ESPECIFIDADE DA GESTÃO DE PESSOAS EM INSTITUIÇÕES EDUCACIONAIS
}

Independentemente da área de conhecimento, o ser humano sempre se faz presente, o que não é diferente quando se trata da área de educação. Como parte de uma organização, o ser humano sofre a influência de vários fatores, dentre eles da comunicação, da motivação, da reciprocidade, da criatividade e do trabalho em equipe 
(PEDRO; OLIVIERI, 2008). Os autores consideram o conhecimento como um tesouro, no entanto, ressaltam de forma enfática que a prática é a chave para o acesso a esse conhecimento.

Na educação, a gestão de pessoas também é de fundamental importância. Para Meyer, Jr. e Sermann (2004), citados por Pedro e Olivieri (2008), a gestão é negligenciada em instituições de ensino, colaborando para a existência de fatores que contribuem com a situação de precariedade das unidades escolares. O primeiro é relacionado ao fato de se atribuir uma dimensão operacional e secundária à gestão da escola. O segundo fator é a inexistência de modelos de gestão específicos para a escola. O terceiro fator é a predominância de uma prática amadora de gestão, sendo identificado que as pessoas que assumem a gestão de escolas não foram preparadas de forma adequada. Pedro e Olivieri (2008) consideram que o trabalho com pessoas exige o entendimento de comportamento humano e o conhecimento de variadas práticas e sistemas já existentes, o que poderá auxiliar para a construção de uma gestão motivada e qualificada. Na educação, se fala muito da relação professor-aluno, no entanto, a relação escola-professor também é importante, e é nesta tríade complexa (aluno-professor-escola) que a gestão poderá mostrar os seus diferenciais. Se na escola não houver a gestão de pessoas de forma adequada, há dificuldades para que o professor utilize todo o seu potencial, a sua inovação e criatividade. Assim, percebe-se a necessidade de se qualificar os gestores que atuam nas escolas, sendo relevante identificar o nível de conhecimento que o gestor possui de sua área de atuação (PEDRO; OLIVIEIRI, 2008).

\section{GESTÃO DE PESSOAS E TRABALHO COLETIVO EM INSTITUIÇÕES EDUCACIONAIS}

Nem sempre um conjunto de pessoas que trabalham em um mesmo local constitui uma equipe. Para que se tenha uma equipe, é necessária a existência de um elemento de identidade, que unirá as pessoas. Essa identidade, que poderá unir as pessoas, se revela nas normas instituídas, nos objetivos, na causa, enfim, no processo (VERGARA, 2016).

$\mathrm{Na}$ organização atual do Sistema Educacional Brasileiro, o dirigente escolar ocupa um papel importante no processo de construção de uma gestão democrática, ou seja, em uma gestão que valoriza a participação das pessoas nas decisões. Leite e Di Giorgi (2004) afirmam que a figura do dirigente educacional vem imediatamente em nosso pensamento quando falamos em gestão de uma unidade educacional. Os autores ainda afirmam que diretor cumpre um papel essencial na administração ou gestão escolar. Quando se pensa em uma gestão que pressupõe a participação das pessoas, é fundamental que a comunidade da instituição educacional tenha a oportunidade de compartilhar os seus desejos, as suas aspirações e, também, o projeto de trabalho da unidade educacional, buscando de forma intensiva a melhoria do ensino. Vitor Henrique Paro (2018) também reconhece como de importância fundamental, no processo que visa à instalação de uma gestão com a participação das pessoas, que a coordenação dos esforços, seja dos funcionários, dos professores, do pessoal técnico-administrativo, dos pais e dos alunos, tenha como fundamento a participação coletiva.

As principais legislações educacionais do país enfatizam a importância da gestão democrática, no entanto, muitos gestores são apontados como obstáculos para uma gestão que valorize a participação das pessoas, que busque um trabalho coletivo. Esses diretores se dedicam, em boa parte do tempo de trabalho, ao controle do trabalho dos seus 
'subordinados' (SILVA, 2006). Se for adotada, na gestão educacional, uma concepção de administração técnico-científica, onde a visão tecnicista e burocrática prevalece, o gestor é considerado a figura principal da instituição educacional, restando às demais pessoas que compõem esse espaço o cumprimento de suas decisões (LIBÂNEO, OLIVEIRA; TOSHI, 2018).

Paro (2003), constatou em pesquisa desenvolvida, que um dos embaraços para o trabalho coletivo era o papel desempenhado pelo diretor escolar, visto como a autoridade máxima da unidade. Em uma gestão educacional que se quer participativa, ou seja, que conte com a participação das pessoas, deverá ocorrer a construção de um coletivo, composto pelos profissionais da educação, pais e alunos, com toque e feição democrática, de forma que a instituição seja transformada em local de aprendizagem para todos (MANSANO, 2010 apud, SILVEIRA JUNIOR; RIBEIRO, 2013). Uma gestão que valoriza o trabalho coletivo se opõe à existência de um diretor que faça valer a sua autoridade. Silveira Junior e Ribeiro (2013) consideram que organizar-se de forma a valorizar o trabalho coletivo pressupõe que a instituição adote uma opção política de se organizar de forma diferente, onde se estimule o maior envolvimento das pessoas e onde há uma meta coletiva com foco no aluno.

\section{A IMPORTÂNCIA DO TRABALHO COLETIVO PARA O ALCANCE DOS RESULTADOS EDUCACIONAIS}

Para entender a importância do trabalho coletivo, visando o alcance dos resultados educacionais, buscamos o auxílio de Sander (1995), que se baseia em uma construção teoricamente denominada "Administração Relevante"2. A Administração Relevante, na concepção de Sander (1995), "é uma derivação conceitual de formulações interacionistas recentes e atuais no campo da teoria organizacional e administrativa preocupadas com as características culturais e os valores éticos que definem o desenvolvimento humano sustentável e a qualidade de vida na educação e na sociedade" (p. 50). No entendimento de que a cultura organizacional pode contribuir para a manutenção das relações de poder no âmbito da organização, bem como para se contrapor a essas relações, essa corrente foca o atendimento dos que sofrem o efeito das organizações, compreendendo as necessidades humanas dessas pessoas.

Há um compromisso dessa administração com a promoção da qualidade de vida e dos valores humanos, onde a participação numa gestão permita que os diferentes interesses e significados tornem-se relevantes. A partir da compreensão e da valorização das diferentes culturas presentes no ambiente escolar, constrói-se uma gestão com a participação da comunidade escolar, permitindo que os diferentes interesses e significados tornem-se relevantes. Para Sander (1995, p. 50), "a relevância (do verbo latino relevare, levantar, salientar, valorizar) é o critério cultural que mede o desempenho administrativo em termos de importância, significação, pertinência e valor”. O mesmo autor ainda afirma que:

Os protagonistas de uma construção de administração relevante adotam uma orientação essencialmente cultural e pautam sua ação pela pertinência e significância dos fatos administrativos para o desenvolvimento humano e a qualidade de vida dos cidadãos que

2 Sander (1995) analisa as concepções de administração da área da educação, apontando a existência de quatro construções teóricas ocorridas em nosso período histórico, sendo elas: a) a Administração Eficiente; b) a Administração Eficaz; c) a Administração Efetiva; e d) a Administração Relevante. 
participam do sistema educacional e da sociedade como um todo (SANDER, 1995, p. 52).

Consoante às dificuldades por que passam os estabelecimentos de ensino e, na busca de um aprimoramento, algumas unidades, sob a coordenação de seus diretores, têm se empenhado para que a comunidade participe de forma mais ativa da administração escolar. Diversas experiências nos mostram que, pelo fato de a comunidade participar da gestão escolar, o trabalho da equipe de direção tem se tornado menos estafante, possibilitando uma melhoria na organização e na qualidade das atividades desenvolvidas. Tais experiências denotam a capacidade da comunidade em assumir maiores compromissos na educação escolar, se comprometendo com todas as atividades desenvolvidas e, consequentemente, atuando para que os resultados educacionais sejam alcançados.

\section{CONSIDERAÇÕES FINAIS}

A administração escolar conseguirá cumprir de melhor forma com as suas funções, atuando para que os resultados sejam alcançados, se contar com a participação dos segmentos escolares, ou seja, através de um trabalho coletivo, de forma que todas as culturas existentes na instituição sejam valorizadas. Mediar as culturas existentes tornase fundamental para que todos se sintam representados nas decisões tomadas, sendo, portanto, uma capacidade imprescindível ao administrador escolar.

A participação da comunidade na escola pode ensejar, dentre outros elementos: - o fortalecimento do Conselho Escolar, passando o colegiado a deliberar sobre assuntos relevantes no contexto escolar, tais como: sobre as prioridades para os recursos financeiros, tendo como princípio a função primordial da escola; sobre as metas pedagógicas a serem atingidas pelo coletivo, a partir de avaliação do trabalho desenvolvido; e sobre os critérios para a atribuição de classes e/ou aulas, dentre outros temas relevantes;

- a realização de um planejamento escolar de forma coletiva, e que contemple as necessidades da escola, buscando a melhoria do trabalho desenvolvido, de forma a que os alunos tenham um ensino de qualidade, ou seja, que dominem os conhecimentos socialmente construídos e estejam preparados para o exercício da cidadania;

- a existência de conselho de classe e/ou ciclo com a participação de todos os segmentos da escola, sendo um momento onde ocorra uma avaliação efetiva do trabalho pedagógico desenvolvido, que passa pela atuação da equipe de direção e dos docentes, enterrando de vez o corporativismo docente visto nesses momentos, onde todos os professores, sendo solidários ao professor responsável pela atribuição de determinado conceito, acompanham a sua decisão;

- a realização de reuniões pedagógicas enquanto momentos para que professores e funcionários possam falar sobre o trabalho desenvolvido e as dificuldades enfrentadas, buscando-se, através de análise de teorias, compreender o que enfrentam e buscar coletivamente elementos que contribuam para a superação dessas dificuldades.

A coordenação desse trabalho, onde a gestão de pessoas busque a participação, para que todos se sintam representados, exige muito preparo da equipe de direção da escola, o que muitas vezes não se obtém no momento da formação inicial de seus integrantes. É preciso buscar esses conhecimentos, e não se acomodar na administração de rotinas. 
Torna-se necessário, portanto, além do domínio dos Fundamentos da Educação, de Contabilidade, e outras áreas do conhecimento, preparo do gestor para coordenar o coletivo escolar, ou seja, para a gestão das pessoas, durante todo o processo de planejamento - elemento fundamental para que a escola cumpra a sua função social -, o que também exige conhecimentos técnicos apurados. É necessário, ainda, o domínio de conhecimentos que possibilitem um acompanhamento do trabalho desenvolvido, sem que se controle as ações em andamento, ou seja, é necessário o despojamento do "poder decidir" que a equipe pensa ter.

A busca de uma Administração Escolar com a participação da comunidade, o fortalecimento do Conselho de Escola e a elaboração do Projeto da escola de forma coletiva constituem-se em meios para que a escola possa cumprir a sua função social, ou seja, transmitir ativamente os conhecimentos construídos socialmente, conhecimentos consoantes aos interesses e necessidades da classe social que a escola pública atende, e que poderão possibilitar aos alunos dessa classe social o atendimento de seus direitos.

Não se pode negar a existência de vários elementos que emperram a organização de um coletivo, como dirigentes escolares autoritários; membros da comunidade escolar desinteressados em decisões cujos benefícios sejam de todos; dependência de que o diretor dê abertura para que professores, pais, alunos e funcionários participem da gestão da escola, ficando todos à mercê do temperamento desse ou daquele gestor. É conveniente lembrar sobre a importância da gestão democrática que, para Ferreira (2015), é indubitável "[...] como um recurso de participação humana e de formação para a cidadania. É indubitável sua necessidade para a construção de uma sociedade mais justa e igualitária. É indubitável sua importância como fonte de humanização" (p. 305). A história educacional brasileira mostra que, sem luta, sem ação dos interessados na melhoria da escola, nada se altera em benefício dos representados. Se há o desejo de uma gestão democrática, de uma comunidade participante, tendo como fim o ensino de qualidade, deve-se agir coletivamente nesse sentido.

Os atuais (e poucos) espaços hoje existentes de participação, sejam eles frutos da concessão dos governantes ou da reivindicação de atores sociais, devem ser devidamente aproveitados, ocupados. Demo (1999) acredita na participação enquanto processo, em seu sentido legítimo. Para o autor, a participação não se completa, não se acaba, mas deve ser constantemente construída. Uma gestão democrática, nela incluída uma maior participação da comunidade nas decisões de interesse coletivo, deve ser permanentemente buscada e planejadamente construída. Ela não acontecerá por acaso, por mágica, por obra divina ou do destino, mas será resultado de um esforço coletivo intencional. Se hoje, por exemplo, a população decide apenas de que forma serão arrecadados recursos para a melhoria da biblioteca escolar, poderá, amanhã, decidir que escola quer para seus filhos. Utopia? Talvez! Entendida enquanto um sonho a ser perseguido.

\section{REFERÊNCIAS}

BOOG, G. G. A excelência na gestão de pessoas e equipes. in: LEITE, B.; FURLAN, J.; SITA, M. (coord.). Ser mais inovador em RH: ideias criativas e novas propostas para o desenvolvimento do capital humano. São Paulo: Ser Mais, 2010. 
BRASIL. Constituição da República Federativa do Brasil. Brasília, 1998. Disponível em: <<http://www.planalto.gov.br/ccivil_03/constituicao/constituicao.htm〉>. Acesso: 07 ago. 2019.

Lei $\mathrm{n}^{\circ}$ 9.394, de 20 de dezembro de 1996. Estabelece as diretrizes e bases da Educação Nacional. Brasília, $1996 . \quad$ Disponível em: <<http://www.planalto.gov.br/ccivil_03/leis/19394.htm>>. Acesso: 07 ago. 2019.

CHIAVENATO, I. Gestão de Pessoas. Rio de Janeiro: Elsevier, 2009.

DEMO, P. Participação é conquista: noções de política social participativa. 4 ed. São Paulo: Cortez, 1999.

DIAZ BORDENAVE, J. E. O que é participação. São Paulo: Editora Brasiliense, 1994.

DRABACH, N. P.; MOUSQUER, M. E. L. Dos primeiros escritos sobre Administração Escolar no Brasil aos escritos sobre gestão escolar. Currículo sem Fronteiras, v.9, n.2, pp.258-285, Jul/Dez 2009. Disponível em: <http://www.curriculosemfronteiras.org/vol9iss2articles/drabach-mousquer.pdf >.

Acesso: 07 ago. 2019.

DUTRA, J. S. Gestão de pessoas: modelo, processos, tendências e perspectivas. São Paulo: Atlas, 2016.

FERREIRA, N. S. C. Gestão democrática da educação: ressignificando conceitos e possibilidades. In: FERREIRA, N. S. C.; AGUIAR, M. Â. da S. (org.). Gestão da educação: impasses, perspectivas e compromissos. São Paulo: Cortez, 2015.

GIL, A. C. Como elaborar projetos de pesquisa. 3. ed. São Paulo: Atlas, 2017.

LEÃO, A. C. Introdução à Administração Escolar. $2^{\mathrm{a}}$ edição. São Paulo: Companhia Editora Nacional, 1945.

LEITE, Y. U. F; DI GIORGI, C. A. G. Ressignificando a função da escola pública e do professor nos dias de hoje: alguns apontamentos. In: SILVA JÚNIOR, C. A.; ARENA, D. B.; LEITE, Y. U. F. Pedagogia Cidadã: Cadernos de formação. São Paulo: UNESP, 2004.

LIBÂNEO, J. C.; OLIVEIRA, J. F. de; TOSCHI, M. S. Educação Escolar: políticas, estrutura e organização. 10 ed. São Paulo: Cortez, 2018.

LIMA, T. C. S. de; MIOTO, R. C. T. Procedimentos metodológicos na construção do conhecimento científico: a pesquisa bibliográfica. Rev. Katál. Florianópolis v. 10 n. esp. p. $37-45 \quad 2007 . \quad$ Disponível em: http://www.scielo.br/scielo.php?script=sci_arttext\&pid=S1414-49802007000300004>>. Acesso: 07 ago. 2019.

LOURENÇO FILHO, M. B. Organização e Administração Escolar: curso básico. 5. Ed. São Paulo, Edições Melhoramentos, 1970.

MANSANO, E. L. de S. Gestão de recursos escolares. São Paulo: Know-How, 2010.

MARCONI, M. A.; LAKATOS, E. M.. Metodologia do trabalho científico: procedimentos básicos, pesquisa bibliográfica, projeto e relatório. 7. ed. São Paulo, Atlas, 2017. 
OZAKI, Y. Dimensão Humana na Governança Corporativa. Departamento de Extensão e Pós-Graduação. Valinhos, 2009. Disponível em: 〈http://anhanguera.com>. Acesso em: 1 fev. 2019.

PARO, V. H. Administração escolar: introdução crítica. 17. Ed. São Paulo, Cortez Editora, 2018.

Eleição de diretores: a escola pública experimenta a democracia. 2. ed. Campinas: Papirus, 2003. Disponível em: $<$ http://www.vitorparo.com.br/trabalhospublicados/livros/download/>>. Acesso: 07 ago. 2019.

PEDRO, M. J. C.; OLIVIERI, M. de F. A. Gestão de pessoas na educação. 2008. Disponível em: <http://www.administradores.com.br/artigos/marketing/gestao-depessoas-na-educacao/23866/>. Acesso: 07 ago. 2019.

RUSSO, M. H. Trabalho e gestão na escola: especificidades do processo de produção pedagógico. 2013. Disponível em: <http://www.anpae.org.br/congressos_antigos/simposio2007/338.pdf>. Acesso: 07 ago. 2019.

RIBEIRO, J. Q. Ensaio de uma teoria da Administração Escolar. São Paulo: Saraiva, 1986.

SANDER, B.. Gestão da Educação na América Latina: construção e reconstrução do conhecimento. Campinas: Autores Associados, 1995.

SILVA, N. R. G. A participação da comunidade escolar como fator de influência na reeleição/não-reeleição dos diretores de escola. Tese de Doutorado. Faculdade de Educação, Unicamp. Campinas, 2006. Disponível em: < http://repositorio.unicamp.br/jspui/handle/REPOSIP/252385>>. Acesso: 07 ago. 2019.

SILVEIRA JUNIOR, O. B. da; RIBEIRO, R. L. Gestão de pessoas na educação. 2013. Disponível em: <http://www.amog.org.br/amogarquivos/TCCPOS/Rozeli-Lucas-MaiaRibeiro-Artigo-Cientifico.doc>. Acesso: 07 ago. 2019.

TEIXEIRA, A. Que é administração escolar? Revista Brasileira de Estudos Pedagógicos, v.36, n.84, p.84-89, 1961.

Educação para a Democracia: introdução à administração escolar. Rio de Janeiro: Editora da UFRJ, 1997.

Natureza e função da Administração Escolar. Cadernos de Administração Escolar, n. 1. Salvador: ANPAE, 1964.

VERGARA, S. C. Gestão de pessoas. 16. Ed. São Paulo, Atlas, 2016. 